\title{
Transition Probability Matrix of Mothers and Newborn Heamoglobin Count in Kanyakumari District
}

\author{
K. Senthamaraikannan", D. Nagarajan" and V. Nagarajan ${ }^{\$}$ \\ \# Department of Statistics, Manomaniam Sundaranar University, Thirunelveli \\ E-mail: senkannan2002@yahoo.com \\ * Department of Mathematics, St. Joseph College of Engineering, Chennai \\ E-mail:dnrmsu2002@yahoo.com \\ ${ }^{\$}$ Department of Computer Science, S.T. Hindu College, Nagercoil \\ E-mail: sthc_rajan@yahoo.com
}

KEYWORDS Hemoglobin count; birth weight; equilibrium state; geometric distribution

ABSTRACT During the last three decades the researches much attention about the mothers and newborn health. Haemoglobin count is one of the main factors in mothers and baby health. The main objective of this paper, to analysis the haemoglobin count for mothers and newborn, uses moments of geometric distribution and equilibrium state. The magnitude of the fall in haemoglobin concentration in pregnancy is related to mothers and babies health, failure of haemoglobin concentration may be indicates risk of mothers and babies health

\section{INTRODUCTION}

During normal pregnancy in women not given supplementary iron. The haemoglobin concentration of the maternal blood falls from a nonpregnant average of about $133 \mathrm{~g} / \mathrm{l}$ to $110 \mathrm{~g} / \mathrm{l}$ at 36 weeks Taylor and Lind (1979). The blood level is steepest up to 20 weeks gestation, the concentration remain fairly constant up to 30 weeks and then rises slightly there after. Paintin et al (1966). Further in any type of haemoglobin concentration taken after 20 weeks gestation will be reasonably induced pregnancy, whether this represents anaemia or not remains controversial issue. The world health organization in its nutritional report of 1972 suggested that anaemia was likely to be present in pregnant women when the haemoglobin fell below $110 \mathrm{~g} / \mathrm{l}$ Horn (1988).

Supplementation of pregnant women with iron and folic acid reduces the incidence of hemoglobin less than $110 \mathrm{~g} / \mathrm{l}$ to fewer than $5 \%$. As a result routine prophylaxis is commonly advocated. Letsky (1994). In contrast, a recent review of 20 randomized controlled trials reported, "routine supplementation has no detectable effect on any substantive measures of either maternal or fetal outcome on preterm delivery, low birth weight still births or neonatal morbidity. The available data from controlled clinical trials provide no convincing case for routine as opposed to selective iron supplementation.

\section{METHODOLOGY}

The data were collected from government general hospital, Nagercoil, Tamil Nadu. During the year June 2005 to July 2006. Those who come far treatment in this hospital. This hospital well equbied and correctly maintained the records of pregnant women and child. The data from the hospital records. The stochastic model is taken to analysis this data because this model only time dependent.

\section{Model Description}

The data's were classified in to four states,

State 1 : less than $100 \mathrm{~g} / \mathrm{l}$

State 2 : $100-110 \mathrm{~g} / \mathrm{l}$,

State 3 : $110-120 \mathrm{~g} / \mathrm{l}$

State 4 : greater than $120 \mathrm{~g} / 1$ hemoglobin concentration.

$$
\text { Let } \quad \mathrm{P}=\left[\begin{array}{cccc}
\mathrm{P}_{11} & \mathrm{P}_{12} & \cdots & \mathrm{P}_{\mathrm{ij}} \\
\vdots & & & \\
\vdots & & & \\
\mathrm{P}_{\mathrm{i} 1} & \mathrm{P}_{\mathrm{i} 2} & \cdots & \mathrm{P}_{\mathrm{ij}}
\end{array}\right]
$$

The mean of geometric distribution is $=\frac{1}{1-\mathrm{P}_{\mathrm{ij}}}$ Variance of the geometric distribution $=\frac{\mathrm{P}_{\mathrm{jj}}}{\left(1-\mathrm{P}_{\mathrm{jj}}\right)^{2}}$ $\operatorname{LimP}_{n \rightarrow \alpha}^{(n)}=P$ is the equilibrium state of given Matrix. 


\section{RESULTS}

From the table 1, 379 data are in Mother and matured Baby Hemoglobin Concentration.

Table 1: Mother and matured baby Baby Hemoglobin

\begin{tabular}{rrrrr}
\hline & $S_{1}$ & $S_{2}$ & $S_{3}$ & $S_{4}$ \\
\hline$S_{1}$ & 0 & 4 & 9 & 2 \\
$S_{2}$ & 6 & 14 & 42 & 23 \\
$S_{3}$ & 4 & 14 & 193 & 28 \\
$S_{4}$ & 2 & 4 & 28 & 6 \\
\hline
\end{tabular}

Table 2: TPM for Mother and Matured Baby

\begin{tabular}{rllll}
\hline & $S_{1}$ & $S_{2}$ & $S_{3}$ & $S_{4}$ \\
\hline $\mathrm{P}=\mathrm{S}_{1}$ & 0 & 0.2667 & 0.6 & 0.1333 \\
$\mathrm{~S}_{3}$ & 0.0706 & 0.1647 & 0.4941 & 0.2706 \\
$\mathrm{~S}_{4}$ & 0.0167 & 0.0586 & 0.8075 & 0.1177 \\
\end{tabular}

$\operatorname{LinP}_{\mathrm{n} \rightarrow 25}^{(\mathrm{n})}=\left[\begin{array}{llll}0.0249 & 0.0776 & 0.7636 & 0.1339\end{array}\right]$

and mean of mother and mature baby using geometric distribution are.

Table 3: Mean and variance

\begin{tabular}{llc}
\hline State & Mean & Variance \\
\hline $\mathrm{S}_{1}$ & 1 & 0 \\
$\mathrm{~S}_{2}$ & 1.201 & 0.3261 \\
$\mathrm{~S}_{3}$ & 5.195 & 21.79 \\
$\mathrm{~S}_{4}$ & 1.176 & 0.2076 \\
\hline
\end{tabular}

From the above results reveals that the highest probability is 0.7636 state one goes to state 3 . it means that the hemoglobin concentration $<100$ $\mathrm{g} / \mathrm{l}$ is goes to $110-120 \mathrm{~g} / \mathrm{l}$. The probability of state one $<100 \mathrm{gl}$ is 0.0249 on the same state. The state one less than $110 \mathrm{~g} / \mathrm{l}$ is goes to state 2 is 0.0776 and state- 1 is goes to state- 4 is 0.1339 . From the mean except state 3 almost same Variance including.

Table 4: Mother and pre-matured baby

\begin{tabular}{|c|c|c|c|c|c|}
\hline \multirow{6}{*}{ 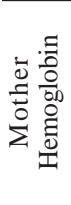 } & \multicolumn{5}{|c|}{ Baby Hemoglobin } \\
\hline & $\overline{\text { State }}$ & $S_{1}$ & $S_{2}$ & $S_{3}$ & $S_{4}$ \\
\hline & $\overline{S_{1}}$ & 1 & 1 & 4 & 4 \\
\hline & $\mathrm{S}_{2}$ & 1 & 1 & 11 & 7 \\
\hline & $\mathrm{S}_{3}^{2}$ & 1 & 3 & 59 & 8 \\
\hline & $\mathrm{S}_{4}^{3}$ & 0 & 1 & 16 & 3 \\
\hline
\end{tabular}

From the table 4, 121 data are in mothers and prematured baby's hemoglobin concentration.

From the above results reveals that the highest probability is 0.8078 state one is goes to state 3 is the hemoglobin concentration $<100 \mathrm{~g} / \mathrm{l}$ goes to $110-120 \mathrm{~g} / \mathrm{l}$. The probability of state one $<100 \mathrm{~g} /$ 1 is 0.0151 on the same state. The state 1 less than $100 \mathrm{~g} / \mathrm{l}$ goes to state 2 is 0.0445 and state 1 is goes to state 4 is 0.1326 .

Table 5: TPM for mother and pre matured babes and mean of mother and pre matured babies using geometric distribution are.

\begin{tabular}{cllll}
\hline & $S_{1}$ & $S_{2}$ & $S_{3}$ & $S_{4}$ \\
\hline $\mathrm{S}_{1}$ & 0.1 & 0.1 & 0.4 & 0.4 \\
$\mathrm{P}=\mathrm{S}_{2}$ & 0.05 & 0.05 & 0.55 & 0.35 \\
$\mathrm{~S}_{3}$ & 0.0141 & 0.0423 & 0.8309 & 0.1127 \\
$\mathrm{~S}_{4}$ & 0 & 0.05 & 0.8 & 0.15 \\
\hline$\underset{n}{\mathrm{Lt} \mathrm{P}}{ }^{(\mathrm{n})}=\left[\begin{array}{llll}0.0151 & 0.0445 & 0.8078 & 0.1326\end{array}\right]$
\end{tabular}

Table 6: Mean and variance

\begin{tabular}{llc}
\hline State & Mean & Variance \\
\hline $\mathrm{S}_{1}$ & 1.111 & 0.1234 \\
$\mathrm{~S}_{2}$ & 1.053 & 0.0554 \\
$\mathrm{~S}_{3}$ & 5.917 & 29.058 \\
$\mathrm{~S}_{4}$ & 1.127 & 0.14315 \\
\hline
\end{tabular}

Table 7: Matured and premature baby and mothers

\begin{tabular}{|c|c|c|c|c|c|}
\hline \multirow{6}{*}{ 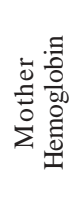 } & \multicolumn{5}{|c|}{ Baby Hemoglobin } \\
\hline & State & $S_{1}$ & $S_{2}$ & $S_{3}$ & $S_{4}$ \\
\hline & $\overline{S_{1}}$ & 1 & 5 & 13 & \\
\hline & $S_{2}^{1}$ & 7 & 15 & 53 & 30 \\
\hline & $\mathrm{S}_{3}^{2}$ & 5 & 17 & 52 & 36 \\
\hline & $\mathrm{S}_{4}^{3}$ & 2 & 5 & 44 & 9 \\
\hline
\end{tabular}

Table 8: TPM for Matured, Pre-matured babies and Mother.

\begin{tabular}{rllll}
\hline & $S_{1}$ & $S_{2}$ & $S_{3}$ & $S_{4}$ \\
\hline $\mathrm{P}=\mathrm{S}_{1}$ & 0.040 & 0.2 & 0.52 & 0.24 \\
$\mathrm{~S}_{3}$ & 0.0667 & 0.1478 & 0.5048 & 0.2857 \\
$\mathrm{~S}_{4}$ & 0.0161 & 0.0549 & 0.6129 & 0.1161 \\
\hline
\end{tabular}

Table 9: Mean and variance

\begin{tabular}{llc}
\hline State & Mean & Variance \\
\hline $\mathrm{S}_{1}$ & 1.042 & 0.0434 \\
$\mathrm{~S}_{2}$ & 1.167 & 0.194 \\
$\mathrm{~S}_{3}$ & 5.345 & 23.22 \\
$\mathrm{~S}_{4}$ & 1.176 & 0.2076 \\
\hline
\end{tabular}

From the mean except state 3 almost same variance including and mean of mother and pre matured babies using geometric distribution are. 
From the above result revels that the highest probability is 0.774 . State 1 is goes to state 3 is the hemoglobin concentration $<100 \mathrm{~g} / \mathrm{l}$ goes to $110-120 \mathrm{~g} / \mathrm{l}$. The probabilities of state $1<100 \mathrm{~g} /$ 1 is 0.0224 on the same state, the state $1<100 \mathrm{~g} / 1$ goes is state 2 is 0.0679 , and state 1 is goes to state 4 is 0.1349 . From the mean except state 3 almost same, variance including.

\section{CONCLUSION}

The magnitude of the fall in hemoglobin concentration in pregnancy is related to birth hemoglobin concentration to fall below $105 \mathrm{~g} / 1$ indicates risk of low birth weight. From the above discuss reveals that the highest probability is state 1 is goes to state 3 , stat 1 - state 4 , state 1 - state 2 and on the same state one. From the moments of geometric distribution, the highest mean is 5.345 states 3 low hemoglobin concentration mother may be delivered 110 to $120 \mathrm{gl} \mathrm{hemoglobin}$ concentration babies. That means after sufficient long time the haemoglobin concentration $100 \mathrm{gl}$ goes to the state $100-120 \mathrm{gl}$. This finding is very useful to reduce the anemia problem and other problems related the low haemoglobin count.

\section{REFERENCES}

Horn, E. 1988. "Iron and folate supplements during pregnancy supplementing every one treats those at risk and is cost effective." BioMedical Journal, 297(1): 1325-1357.

Letsky, E.A, R. Warwick, D. K. James, P. J. Steer, C. P. Weiner and B. Goniks (Eds.). 1994. Heamatological Problems in High Risk Preganancy: Management Options. London: W.B. Saunders.

Meng Lu, Z. Goldenberg, R.L. Clivers, G. Cutter and M. Brankson. 1991. "The relationship between maternal hematocrit and pregnancy out come." Obstet. Gynecol., 77(1): 190-204.

Philip Steer, U. Kondaveeti, C. Barry-Kinsella.1995. "Relation between maternal heamoglobin Concentration and birth weight in different ethnic graphs" Bio Medical Journal, 310(1): 489-491.

Paintin, D.B., A. M. Thomson and E. E. Hytten. 1966. "Iron and the hemoglobin level in pregnancy." $J$. Obstel. Gynaecol., 73(1): 181-190.

Taylor, D.J. and T. Lind. 1979. "Red cell mass during and after normal pregnancy." J. Obstet. Gynaecol., 86(1): 364-370. 